\title{
DOIS OLHARES SOBRE A MIGRAÇÃO INTERNACIONAL NO NORDESTE BRASILEIRO
}

\author{
Marcelo Alario Ennes ${ }^{1}$ \\ Rosinadja Morato ${ }^{2}$ \\ Caio Ferreira dos Santos ${ }^{3}$
}

\section{Resumo:}

O objeto do presente artigo são as imigrações internacionais para a região Nordeste do Brasil. Delimitamos o estudo em três grandes períodos. O primeiro compreende as últimas décadas do século XIX e a década de 1940. O segundo período, começa no Pós-Guerra e vai até o final 1980. O último começa na década de 1990 e se encerra em 2018. As questões que procuramos responder foram: quem são os imigrantes? Como eles se inseriram na região? E quais os desdobramentos econômicos, políticos, sociais e culturais? O estudo que deu origem a este artigo foi motivado pela necessidade de conhecer e dar maior visibilidade a presença migrante no Nordeste. Para respondermos nossas questões nos baseamos em dois olhares. O primeiro foi lançado a partir das pesquisas desenvolvidas no âmbito do Grupo de Estudos e Pesquisa "Processos identitários e Poder" - GEPPIP/UFS e o segundo a partir das dissertações e teses produzidas nos programas de pós-graduação da região. Como resultado identificamos que os fluxos foram mais intensos no primeiro e no terceiro períodos, que no primeiro estiveram presentes imigrantes originários da Europa e no terceiro estes estão acompanhados por imigrantes originários da Ásia e da África. Estes imigrantes se inseriram como trabalhadores, empresários e estudantes. Sua presença gerou questões políticas, econômicas, sociais e culturais. Muitas vezes estas questões se sobrepuseram, por exemplo, em torno de práticas econômicas e/ou políticas com a religiosidade e etnicidade entre imigrantes e brasileiros.

Palavras-chave: Imigração. Nordeste. Produção acadêmica.

\section{TWO PERSPECTIVES ABOUT THE INTERNATIONAL MIGRATION IN BRAZILIAN NORTHEAST}

\begin{abstract}
:
The object of this article is the international migration to the Northeast Brazilian region. We have delimited the study into three periods. The first one was the the second half of the 19th century to the 1940s, the second one was from the Post-War until the 1980s, and the last one was from the 1990s until 2018. We seek to answer the following questions with our study: a) Who are the immigrants? b) How did they insert themselves? What were the consequences of their presence under social, economic, political, and cultural aspects? The study based on this article was motivated on the necessity of knowing and giving more visibility to immigrants' subject in the Brazilian Northeast. The search to responses to our research questions was based on two perspectives. The first one, on the studies developed by the study and research group on "Identifying Processes and Power" of Universidade Federal de Sergipe (GEPPIP/UFS) and the second one on thesis and dissertations produced by Graduate Programs of Northeast States. As

\footnotetext{
${ }^{1}$ Pós-Doutor pelo Centro de Estudos sobre Migrações e Relações Interculturais - CEMRI/UAb/Portugal. Doutor em Sociologia pela Universidade Estadual Paulista - UNESP/Araraquara. Docente do Departamento de Ciências Sociais e do Programa de Pós-Graduação em Sociologia - PPGS, ambos da Universidade Federal de Sergipe UFS. Líder do Grupo de Estudos e Pesquisa "Processos Identitários e Poder" - GEPPIP. E-mail: prof.marcelo.ennes@gmail.com.

${ }^{2}$ Doutoranda no Programa de Pós-Graduação em Sociologia - PPGS/UFS. Membro Grupo de Estudos e Pesquisa "Processos Identitários e Poder"- GEPPIP. E-mail: rosinadja@yahoo.com.br.

${ }^{3}$ Graduando em Ciências Sociais/UFS. Membro Grupo de Estudos e Pesquisa "Processos Identitários e Poder" GEPPIP. E-mail: f7caio@gmail.com
} 
a result, we identified that the immigrants' flow in the first and third periods was more intense. We observed that in the first period the immigrants came from Europe and in the third, came from Europe, Asia, and Africa. These immigrants inserted themselves as workers, businessmen, and students. Their presence brought political, social, economic, and cultural changes. These changes, mostly overlapped, for instance, religion had importance in social and economic insertion of these immigrants in the cities where they have lived

Keywords: Immigration. Northeast Brazilian. Academic production.

\section{Introdução}

Há imigrantes na região Nordeste do Brasil? O que eles vieram fazer nesta região considerada sem grande interesse para homens e mulheres nascidos em outros países? De onde e por que vieram? Como se inseriram nas sociedades locais? Foram bem aceitos? Quais foram as marcas sociais, políticas, econômicas e culturais que vêm deixando para as cidades para as quais se dirigiram? O objeto de análise do presente artigo consiste nos fluxos migratórios internacionais para a região Nordeste e procura responder, ainda que parcialmente, as questões acima elencadas. Para tanto, foram considerados três diferentes períodos. O primeiro está compreendido entre o final do século XIX até a Segunda Guerra Mundial; o segundo período vai dos anos que imediatamente sucedem ao final da Guerra e se estende até a década de 1980; e o terceiro começa em 1990 e finaliza em 2018. Nosso principal objetivo é dar maior visibilidade aos fluxos migratórios na região, historicamente considerada como de menor presença de imigrantes quando comparada a outras regiões brasileiras.

As informações aqui apresentadas, longe de pretender esgotar toda a realidade social produzida pela presença de imigrantes nos vários estados do Nordeste, apresentam-se como importantes para contribuir com a inserção da região em um debate essencialmente acadêmico mais amplo, mas também político, talvez em caráter nacional, sobre a imigração. Ainda hoje, são pouco conhecidas as experiências imigratórias nesta parte do Brasil e, não raro, considerada inexistentes. $\mathrm{O}$ artigo se mostra relevante porque permite conhecer os esforços de pesquisadores formados nas universidades da região e, também, por aqueles migram de seus estados de origem para atuar junto a programas de pós-graduação, grupos e centros de pesquisa. Este fenômeno, somado às iniciativas já existentes, têm contribuído para a inserção e o fortalecimento das imigrações internacionais como temática de estudos, e vem formando um número considerável de novos mestres e doutores especializados nesse tema. $\mathrm{O}$ presente artigo pretende contribuir ainda, ao dar maior visibilidade à produção dos cursos de mestrado e doutorado das universidades da região que têm se voltado ao tema das imigrações. Isto é, contribui no sentido de difundir a produção local sobre a temática.

Os dados aqui apresentados e analisados têm origem em relatórios de pesquisas, dissertações de mestrado e teses de doutorado desenvolvidos no Programa de Pós-Graduação em Sociologia (PPGS) da Universidade Federal de Sergipe (UFS), mais especificamente, no âmbito do Grupo de Pesquisa Processos Identitários e Poder (Geppip). Além disso, busca evidenciar as produções de outros programas de universidades situadas na região, com ênfase na temática imigrações. Para acessarmos a produção dos demais Programas de Pós-Graduação, nos utilizamos do catálogo de dissertações e teses da CAPES, que tem servido de base para a elaboração de um banco de dados sistematizado desta produção. As variáveis trabalhadas concentram-se com 
base no grupo estudado, no nível do trabalho de conclusão de curso, universidade e área de conhecimento, local e período estudado, bem como, o enfoque das pesquisas. Trata-se, portanto, de um artigo baseado na produção de programas de pós-graduação das universidades dos estados da região.

Deste modo, procuramos atingir nossos objetivos a partir de dois olhares. O primeiro lançado da experiência como pesquisadores e como observadores que atuam profissional e academicamente em um dos estados do Nordeste. O segundo, amparados pelo levantamento, sistematização e análise, ainda que parcial, das dissertações e teses desenvolvidas em cursos de mestrado e doutorado instalados nos demais estados nordestinos.

\section{Imigração no Nordeste}

Historicamente, quando comparada com as regiões sul e sudeste, o Nordeste brasileiro apresenta um menor número de imigrantes. Isto, no entanto, não quer dizer que a presença de imigrantes não tenha sido ou que não seja importante para compreender a realidade da região, seja do ponto de vista econômico, seja do ponto de vista social e político, ou seja no que diz respeito ao tema que mais nos interessa, que é o da produção da diversidade cultural e das identidades.

De acordo com os dados da Polícia Federal, relativos aos imigrantes documentados, em 2019 o Nordeste registrou 80.240 imigrantes (vide Tabela 1).

\section{Tabela 1}

Registros de imigrantes ativos por região no Brasil em 2019

\begin{tabular}{lcc}
\hline \multicolumn{1}{c}{ REGIÃO } & $\mathbf{N}^{\mathbf{0}}$ DE IMIGRANTES & $\mathbf{( \% )}$ \\
\hline Norte & 128.668 & $10,15 \%$ \\
Nordeste & 80.249 & $6,33 \%$ \\
Centro-Oeste & 62.901 & $4,96 \%$ \\
Sul & 229.945 & $18,13 \%$ \\
Sudeste & 766.116 & $60,42 \%$ \\
Total & $\mathbf{1 . 2 6 7 . 8 7 9}$ & $\mathbf{1 0 0 \%}$ \\
\hline
\end{tabular}

Fonte: Elaborado pelos autores a partir de dados da Polícia Federal - MJSP (2019).

O Estado da Bahia lidera essa lista com 26.854 registros, seguido dos estados do Ceará com 16.157 e Pernambuco com 12.901. As três últimas posições são ocupadas pelos estados do Piauí com 2.026, Sergipe com 2.357 e Alagoas com 3.111, conforme pode ser observado na Tabela 2 . 


\section{Tabela 2}

Registros de imigrantes ativos por unidade federativa do Nordeste brasileiro em 2019

\begin{tabular}{ccc}
\hline UF DE REGISTRO & TOTAL DE MIGRANTES & $\mathbf{( \% )}$ \\
\hline Bahia & 26.854 & $33,47 \%$ \\
Ceará & 16.157 & $20,14 \%$ \\
Pernambuco & 12.901 & $16,08 \%$ \\
Rio Grande do Norte & 8.223 & $10,25 \%$ \\
Maranhão & 4.488 & $5,59 \%$ \\
Paraíba & 4.123 & $5,14 \%$ \\
Alagoas & 3.111 & $3,88 \%$ \\
Sergipe & 2.357 & $2,94 \%$ \\
Piauí & 2.026 & $2,52 \%$ \\
Total & 80.240 & $100,00 \%$
\end{tabular}

Fonte: Elaborado pelos autores a partir de dados da Polícia Federal - MJSP (2019).

De acordo com Bomtempo e Ferreira (2018), pode-se dizer que há uma relação proporcionalmente direta entre dinamicidade econômica e a presença de imigrantes. No mesmo artigo, as autoras abordaram a importância da dinâmica econômica estadual para a atratividade na rota dos fluxos migratórios, a exemplo do Ceará que está posicionado no topo da lista e possui políticas econômicas que favoreceram investimentos e, posteriormente, a atração para mão de obra.

Além destas informações, antes de adentrar nestas duas frentes de análise sobre a imigração no Nordeste, é preciso registrar que a questão das migrações internacionais e do refúgio no Brasil, inclusive, na região, tem sido fortemente afetado pela presença venezuelana (BAENINGER, DEMÉTRIO, DOMENICONI, 2020). De acordo com dados da OIM de janeiro de 2020, os estados do Nordeste receberam 1854 refugiados pela Operação Acolhida. Um pouco mais da metade desses refugiados está distribuída entre os Estados de Pernambuco e da Paraíba. A participação nordestina no Projeto, que concentra o número de refugiados nas regiões Sul e Sudeste, a coloca como a região com o menor número de acolhimentos, mas a mantém no mapa do Projeto mantido pelo Governo Federal e pela ACNUR.

\section{Olhar 1 - Panorama sobre a imigração no Nordeste.}

No que diz respeito ao olhar mais panorâmico sobre imigração no Nordeste, partimos de uma perspectiva bastante ampla sobre quem são as/os imigrantes na região. Este olhar é, inclusive, ancorado na nova Lei n ${ }^{\circ} 13.445$ de 24 de maio de 2017, na qual o imigrante é definido como "pessoa nacional de outro país ou apátrida que trabalha ou reside e se estabelece temporária ou definitivamente no Brasil" (BRASIL, 2017). Neste sentido, estamos chamando de imigrantes tanto trabalhadores, quanto empresários, além, de estudantes de outros países que passaram a viver, trabalhar e/ou estudar nos estados da região.

Sobre os trabalhadores, temos encontrado informações bastante interessantes tais como o fato de a qualificação dos imigrantes e sua remuneração estar acima da média local. Neste caso, estamos falando de um tipo de imigrante mais qualificado do ponto de vista da escolaridade e profissional. A partir de perspectivas um pouco mais amplas, abordando as 
capitais dos estados que compõem as regiões Norte e Nordeste como um todo, Morato (2018) realizou estudo exploratório-descritivo com base nos dados da RAIS 2016. Como resultado, foram encontrados cerca de 13 mil imigrantes, residentes em sua maioria nas capitais, majoritariamente do sexo masculino e com idade entre 30 e 49 anos. A maior parte com formação superior e trabalhavam na iniciativa privada com contrato CLT, ganhando em média até 6 salários-mínimos. Nos últimos 10 anos, este número quadruplicou e os maiores emissores de imigrantes para as regiões Norte e Nordeste foram Portugal e Haiti, seguidos da Coréia.

$\mathrm{O}$ impacto que esses imigrantes ocasionam na economia regional pode, também, ser visualizado por meio dos dados sobre investimentos realizados nos estados da região. De acordo com Bomtempo e Ferreira (2018), verifica-se que além de integrarem a economia regional como consumidores e comerciantes, imigrantes como os chineses, sul-coreanos, portugueses e italianos, também podem atuar como investidores.

Percebe-se, ao analisar o gráfico 1, que o Ceará possuiu a maior parte dos investimentos realizados por migrantes internacionais com autorizações de residência no Brasil. Assim como foi abordado por Bomtempo e Ferreira (2018), podemos inferir que esse forte investimento no estado do Ceará é resultado das políticas econômicas que favoreceram a atração de investimentos externos mediante, por exemplo, a implantação de multinacionais financiadas por capital estrangeiro. Também é possível compreender as repercussões positivas que tal ação efetuou na economia do estado, que conforme apresentado anteriormente, também o faz ser bastante atrativo para migrantes internacionais em busca de oportunidades de sucesso profissional.

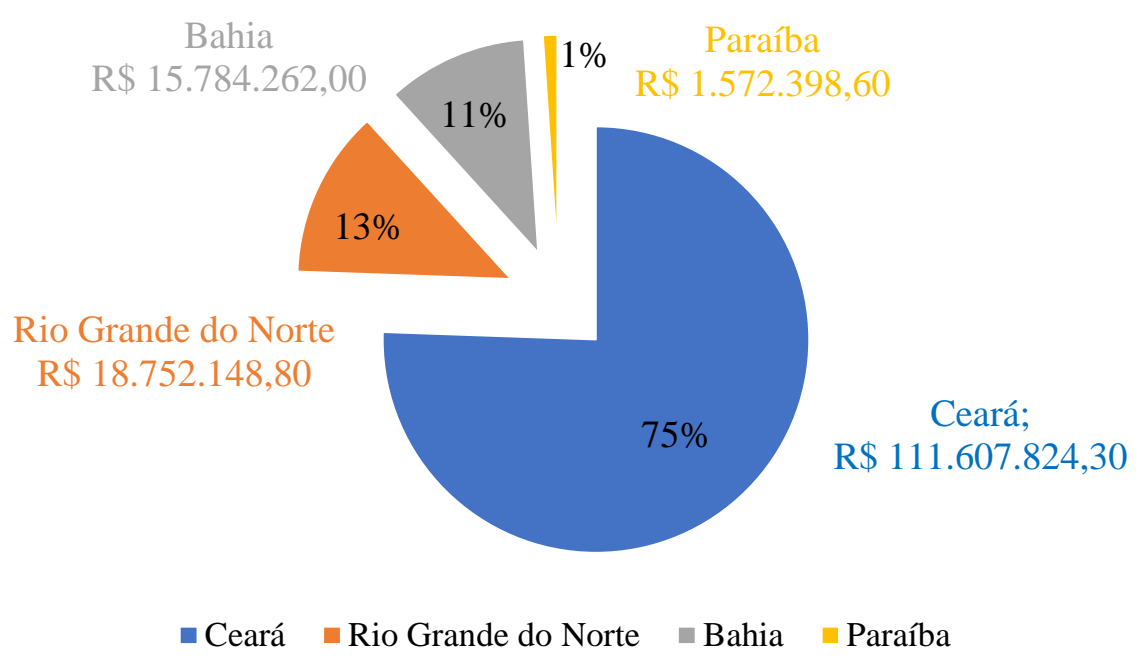

Fonte: Elaborado pelos autores a partir dos dados do OBMigra consoante a Coordenação Geral de Imigração /MJSP, 2018.

\section{Gráfico 1 - Valor dos investimentos (em reais) realizados segundo pessoa física com autorização de residência por Resolução Normativa 13, de acordo com os estados do nordeste mais investidos em 2018}

Quando nos referimos aos empresários, estamos pensando em iniciativas que envolvem grandes aportes de capital, como o setor imobiliário e o hoteleiro (OLIVEIRA, 2018), o que em termos quantitativos representa uma pequena fatia dos imigrantes, mas em termos financeiros é uma realidade bastante significativa. Mas nós também estamos falando dos pequenos e médios 
empresários, os chamados empreendedores (PEREIRA, GOES, ENNES, 2020). Em um estudo realizado sobre imigração no Estado de Sergipe, Ennes (2011) identificou a presença de italianos e alemães na condição de proprietários de Casas Comerciais nas cidades de Maruim e Laranjeiras, na segunda metade do século XIX, e sua atuação no ramo da exportação e importação.

Nos dias atuais, este segmento de empresários imigrantes é representado majoritariamente por chineses e sul-coreanos e merece atenção. Eles não estão apenas nas capitais nordestinas, mas, também, em cidades do agreste como Caruaru, em Pernambuco. $\mathrm{O}$ agreste é formado por um cinturão de cidades médias. As principais cidades desta região, presente em grande parte do Nordeste, são: Feira de Santana (BA), Itabaiana (SE), Arapiraca (AL), Caruaru (PE) e Campina Grande (PB). Estas cidades são grandes centros comerciais, são as cidades das grandes feiras regionais e, portanto, com forte atividade comercial e de distribuição de mercadorias, a exemplo de Itabaiana (SE). Este perfil econômico e o potencial, por assim dizer, geográfico, tem atraído imigrantes que de uma maneira geral são conhecidos por sua inserção no comércio, a exemplo dos chineses e sul-coreanos. Não se trata de grandes comerciantes, mas de pequenos e médios empresários do setor alimentício, de vestuário e de produtos importados que chegam e se estabelecem por meio de suas próprias redes e mecanismos étnicos de solidariedade (PEREIRA, GOES, ENNES, 2020).

Tanto no que diz respeito aos grandes empresários do setor imobiliário e hoteleiro, quanto aos pequenos e médios empreendedores do setor alimentício e de vestuário, esses imigrantes têm imprimido uma nova realidade, ao menos, nas principais cidades da região Nordeste, o que gera uma interessante agenda de estudos voltada, por exemplo, às relações com os comerciantes locais, às disputas pelos negócios e pelo mercado. Esta presença econômica, por sua vez, se desdobra em outras dimensões importantes sobre a sociabilidade, etnicidade e sobre os contrapontos entre identidades e alteridades suscitadas não apenas pelas tensões com comerciantes locais, mas, também, pela presença de suas crianças nas escolas; na existência de políticas locais de acolhimento que possa se refletir no sistema de saúde e educacional; e no surgimento das "colônias" de novos imigrantes na região e todos os seus desdobramentos, cuja história da imigração no Brasil já nos ensinou, sobre participação política, trajetórias profissionais etc. (FAUSTO, 1991, 1995; GRÜN, 1992; KLEIN, 1994; SALLES, 1997; SAKURAI, 1993; TRUZZI, 1997).

Um terceiro grupo que tem aparecido de maneira crescente, tanto nas estatísticas quanto nas pesquisas e publicações, é constituído por estudantes imigrantes. Particularmente de estudantes originários de países africanos e latino-americanos. Estes estudantes estão localizados em alguns estados que abrigam universidades que foram criadas com esta proposta de acolher estudantes de outras nacionalidades. Este é o caso da Universidade da Integração Internacional da Lusofonia Afro-Brasileira (UNILAB), cuja sede administrativa está no município de Redenção, no estado do Ceará, mas que possui campus também na cidade de São Francisco do Conde, na região do Recôncavo Baiano.

De acordo com dados da própria UNILAB (2020), no segundo semestre de 2019, cerca de $25 \%$ de seus alunos de graduação eram imigrantes e na pós-graduação somavam 7,5\%. Há também estudantes imigrantes nos demais estados de modo mais pulverizado, mas não há dados sistematizados sobre isto. 


\section{Olhar 2 - Imigrantes como tema de estudos em universidades do nordeste}

A partir de um levantamento feito no catálogo online de dissertações e teses da Capes, encontramos cerca de 45 dissertações e teses sobre a temática distribuídas nas diversas universidades nos último 30 anos, isto é, sem considerar trabalhos anteriores e sem considerar a publicação destas dissertações e teses sob as formas de artigos e livro. Mesmo que não tenhamos realizado nenhuma análise comparativa com outras regiões, consideramos que este número é significativo e que, de partida, demonstra que há pesquisadores interessados em estudar o tema das migrações internacionais no Nordeste, o que, por sua vez, revela sua importância no plano social e empírico.

A grande maioria dos trabalhos de conclusão de curso em nível de Pós-Graduação Stricto Sensu foi desenvolvida como dissertações de mestrado. De acordo com o levantamento realizado, as dissertações de mestrado representam cerca de $2 / 3$ dos estudos. Isto pode estar associado, entre outros fatores ao fato de alguns programas de pós-graduação não ofertarem cursos de doutorado, principalmente àqueles instalados mais recentemente.

A produção de dissertações e teses sobre migrações internacionais está concentrada em três estados, sendo que Pernambuco se destaca com 44\% dos trabalhos, seguido pela Bahia e Ceará com $26 \%$ e $16 \%$, respectivamente. Observa-se que não foram encontradas nenhuma dissertação ou tese sobre tema nos estados de Alagoas e Piauí.

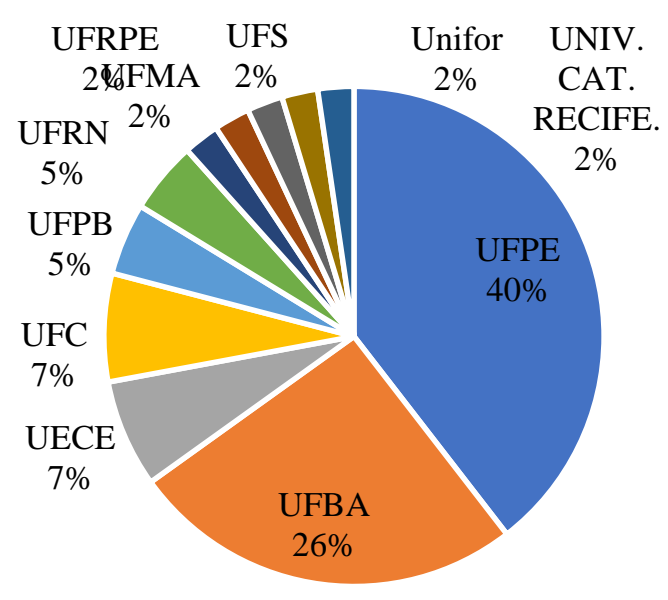

Fonte: Elaborado pelos autores a partir da pesquisa feita em repositórios online

\section{Gráfico 2 - Dissertações e teses segundo IES}

O gráfico 2 revela-nos a distribuição dos estudos pelas universidades. Destaca-se que $40 \%$ das dissertações e teses sobre migrações internacionais no Nordeste foram defendidas na Universidade Federal de Pernambuco e cerca de $1 / 4$ dos trabalhos foram desenvolvidos na Universidade Federal da Bahia. No Ceará, o número de pesquisas sobre o tema está dividido, principalmente, entre a Universidade Federal e Universidade Estadual daquele estado. Como se pode notar as universidades federais, concentram quase a totalidade dos estudos, merece, no entanto, destaque a Universidade Estadual do Ceará que vem produzindo vários estudos sobre o tema. 


\section{Tabela 03}

Dissertações e teses por área de conhecimento dos PPGs

\begin{tabular}{lcc}
\hline Área & Número & \% \\
\hline História & 14 & 32,6 \\
Antropologia & 11 & 25,6 \\
Ciências Sociais & 4 & 9,3 \\
Sociologia & 4 & 9,3 \\
Psicologia & 1 & 4,7 \\
Políticas públicas & 2 & 4,7 \\
Ciência Política & 1 & 2,3 \\
Ciências da Religião & 1 & 2,3 \\
Cultura e sociedade & 1 & 2,3 \\
Desenvolvimento urbano & 1 & 2,3 \\
Educação & 1 & 2,3 \\
Música & 1 & 2,3 \\
\hline Total & 43 & 100,0 \\
\hline
\end{tabular}

Fonte: Elaborado pelos autores a partir da pesquisa feita em repositórios online

A tabela 03 apresenta informações sobre como as dissertações e teses estão distribuídas segundo as áreas de conhecimento dos programas de pós-graduação na região Nordeste do Brasil. Como podemos observar cerca de 1/3 dos trabalhos foram desenvolvidos em cursos de mestrado e doutorado em História. Outra parcela ainda mais significativa, quase metade destes estudos, cerca de $46 \%$, foram defendidos em programas de ciências sociais ${ }^{4}$. Entre estes, os de Antropologia são os mais representativos e reúnem $1 / 4$ de todas as dissertações e teses defendidas no período de acordo com os dados obtidos. Na sequência aparecem os cursos de Ciências Sociais propriamente ditos e os de Sociologia. Ainda que seja necessária uma investigação mais aprofundada, pode-se dizer que esta distribuição se explica, como veremos mais adiante, pelo interesse em estudos sobre imigração no final do século XIX e início do século XX.

Os trabalhos reunidos foram divididos em três períodos de acordo o recorte temporal que as/os autoras/es adotaram. O primeiro período investigado compreende as últimas três décadas dos séculos XIX e as quatro primeiras décadas do século XX; o segundo período inicia no Pós-Guerra e vai até o final da década de 1980; e o terceiro período compreende a década de 1990 e as duas primeiras décadas do século XXI. A escolha por esta divisão temporal está associada às diferenças que cada destes períodos possui no que diz respeito tanto ao contexto internacional quanto aos fluxos migratórios a eles relacionados.

Com base no material coletado, verifica-se que no primeiro período há maior diversidade de nacionalidades em comparação com os dois seguintes. Neste período, observase uma maior concentração de estudos que focam no fenômeno migratório de um modo geral e

\footnotetext{
${ }^{4}$ As ciências sociais possuem três áreas básicas: a Antropologia, a Sociologia e a Ciência Política. A CAPES reconhece quatro possibilidades de cursos de pós-graduação na área: ciências sociais, Antropologia, Ciência Política e Sociologia.
} 
não em uma nacionalidade em específico. Neste caso, os espanhóis são o grupo que aparece como maior frequência seguindo de alemães, japoneses e portugueses.

Em seu conjunto, no que diz respeito aos temas abordados, as dissertações e teses consultadas relevam estudos de caráter transversal. Assim, temas relacionados à economia, política e sociabilidades/etnicidades são sobrepostos, ou melhor, se revelam de modo interdependente.

A importância política de imigrantes no final do século XIX e início do século XX pode ser conhecida, por exemplo, por meio da participação de religiosos capuchinhos italianos na reforma religiosa no sertão da Bahia que teriam atuado na contenção da laicização no Brasil (SOUZA, 2005). Neste mesmo contexto, Lira (1982) estudou políticas e experiências de colonização com brasileiros e estrangeiros na Bahia. Neste estudo destacou a importância da oligarquia baiana na condução deste processo.

A dimensão política da presença de imigrantes e seus desdobramentos na vida social das cidades para onde se destinaram pode também ser observada no sentido oposto. Se este estudo de Souza (2005) revela que imigrantes, nesse caso religiosos, tentaram intervir na organização do estado brasileiro, o inverso também ocorreu e de modo mais frequente. Isto é, o Estado brasileiro agiu de modo a restringir liberdades e direitos de imigrantes. É o que foi debatido em três estudos sobre o período do Estado Novo. Lacerda (2006) estudou a ação do estado e da repressão policial contra grupos considerados perigosos, especialmente alemães, na cidade de Recife. A capital de Pernambuco volta a ser estudada por Lewis (1997) sob a ótica da ação repressiva do Estado Novo contra grupos considerados como ameaça no contexto da Segunda Guerra Mundial. O mesmo contexto é o pano de fundo da dissertação de mestrado de Lima (2004) ao se voltar para as estratégias da comunidade judaica para manter sua identidade no contexto do Estado Novo e Segunda-Guerra. Outra dimensão política é investigada por Freire (2014) ao estudar a reação da população contra imigrantes originários de países que formavam o Eixo. Neste caso, o autor retrata ação de depredação por parte da população contra imóveis de imigrantes na cidade de Fortaleza.

A dimensão econômica neste período de análise é abordada seja da perspectiva da necessidade de mão de obra, seja relacionada ao acesso à terra, seja ainda pela presença de imigrantes no comércio de algumas das capitais nordestinas. No primeiro caso, a presença chinesa é estudada como mão de obra na região Nordeste na atividade agrícola ao longo do século XIX (PERES, 2013).

O tema da relação entre mão-de-obra imigrante e trabalho escravo volta a ser tema de pesquisa, agora no contexto das décadas finais do século XIX e é analisada por meio do estudo dos impasses políticos e econômicos que cercaram o debate sobre colonização e imigração nos anos da escravidão em Pernambuco (ARAÚJO, 1988). A importância do imigrante no desenvolvimento econômico, no caso no Estado de Bahia, é o tema de pesquisa de Lima (2010) ao estudar a importância de comerciantes italianos na cidade de Alagoinha no contexto da expansão ferroviária para a cidade.

O acesso à terra no contexto imigratório é um dos eixos de análise da dissertação de mestrado de Sanchez Martin (1979), que investiga os fatores de expulsão da Espanha e atração do nordeste brasileiro na passagem do século XIX para o XX. O estudo também enfoca as mudanças culturais do grupo a partir da categoria de aculturação o que aproxima o trabalho daqueles que, como veremos, se voltam aos temas da sociabilidade e etnicidade. Esta relação 
reaparece no estudo sobre inserção de imigrantes libaneses no comércio da cidade de Fortaleza a partir da categoria de sociabilidade, redes étnicas etnicidades com base na diferenciação do grupo que eram reconhecidos como "galegos" pela população local. (FRANKLIN, 2011).

A inserção de imigrantes no comércio de capitais nordestinas foi tema da dissertação de mestrado de Câmara (2012) que investigou o tema por meio dos conflitos políticos e econômicos envolvendo portugueses e brasileiros em torno da disputa pelo comércio de retalhos em meados do século XIX em Pernambuco. Este recorte analítico já havia sido adotado por Monteiro (1985) que se dedicou a compreender a presença e a importância econômica de imigrantes portugueses na Bahia na segunda metade do século XIX.

Ainda sobre a importância de imigrantes para as capitais da região, Ludermir (2005) estudou a presença dos judeus, no período do final do século XIX e primeiras décadas do século $\mathrm{XX}$, e sua importância na produção do espaço urbano em Recife, mais especificamente, a influência do grupo na formação espacial e urbanística do bairro da Boa Vista em Recife, na primeira metade do século XX. As sobreposições entre questões econômicas, políticas e de etnicidade entorno do debate sobre colonização reaparece em estudo sobre o final da escravidão em Pernambuco (ARAÚJO, 1988).

Magalhães (2009) estudou a inserção de imigrantes sírio-libaneses em São Luís a partir das disputas simbólicas, econômicas e políticas com a população local. O mesmo enfoque orienta o estudo sobre a presença alemã em Salvador nas últimas décadas do século XIX. A sociabilidade do grupo, isto é, sua inserção social, manutenção e reprodução de práticas culturais e relações com a sociedade local foram estudadas por Rabelo (2009). Esta mesma sobreposição reaparece no estudo sobre judeus em Pernambuco agora no contexto do início do século XX quando a importância do Klientelshik foi investigada por Fonseca (2002) como prática religiosa judaica na orientação de práticas econômicas, especialmente, no comércio ambulante, no interior da comunidade judaica, marcada pela solidariedade étnica em Recife, no início do século XX.

No período entre o Pós Segunda Guerra e a década de 1980, foram encontrados apenas dois estudos. Isto pode ser explicado, pelo menos em parte, pelo decréscimo nos fluxos migratório para o Brasil, inclusive para a região Nordeste. Em ambos os estudos a questão identitária entre imigrantes e seus descendentes aparece como central. No primeiro, uma pesquisa sobre uma colônia de imigrantes japoneses no sul da Bahia e sobre as mudanças identitárias vivenciadas pelo grupo. O estudo se volta para as questões identitárias e os processos de mudanças culturais vivenciados pelo grupo com o passar do tempo (JESUS, 2015). O segundo estudo enfoca a imigração portuguesa no pós-guerra e o antilusitanismo em Recife. A dissertação de mestrado analisa os novos fluxos de imigração portuguesa à luz da Constituição Federal de 1946 e de relatos de imigrantes (FERRAZ, 2014).

$\mathrm{O}$ interesse por questões migratórias volta a crescer com o aumento dos fluxos migratórios no Nordeste nos trinta anos compreendidos entre a última década do século XX e as duas primeiras do século XXI. Neste contexto, os judeus voltam a receber a atenção de vários trabalhos de dissertação e tese desenvolvidos nos programas de pós-graduação da região.

Assim, há o interesse em estudar as diferenças religiosas no interior da comunidade judaica na cidade de Recife (SILVA, 2007), bem como sua a presença na capital pernambucana e aspectos identitários, em especial relacionados à religiosidade, sobre manutenção e dissolução do grupo em confronto com a comunidade local (KAUFMAM, 1991). Outra abordagem é 
encontrada na pesquisa sobre disputas religiosas identitárias no interior da comunidade judaica em Recife nas últimas três décadas do século XX (BRITO, 2014)

O tema da etnicidade judaica reaparece na dissertação de mestrado de Oliveira (2008) que analisa o papel da escola israelita na "preservação" da identidade do grupo entre descendentes de Judeus em Recife. A presença judaica é investigada, também, a partir da importância da música como elemento produtor da etnicidade entre descendentes de judeus na cidade do Recife (CUNHA, 2011). Na mesma cidade, os judeus e seus descendentes foram o tema da dissertação de Munz (2008). Seu estudo investiga como questões contemporâneas relativas às relações entre Israel e Palestina reverberam entre a comunidade judaica no que diz respeito a sua identidade.

Além dos estudos sobre judeus em Recife, nosso levantamento identificou a dissertação de mestrado de Tavares (2003) que realizou uma investigação sobre identidade de descendentes do grupo em uma instituição israelita de caráter religiosa na cidade de Fortaleza. A capital cearense volta a ser o palco do estudo na dissertação de Ricardo (2017), que investiga a importância das redes sociais frente a ausência de políticas públicas voltadas para imigrantes no município de Fortaleza.

Os chineses voltam a ser tema de pesquisa no início do século XXI. Encontramos três estudos sobre o grupo em três estados diferentes. O primeiro nas cidades do Recife e de Caruaru, nos quais os chineses são estudados por Silva (2008) a partir da sobreposição já observada em estudos sobre os grupos entre atividades econômicas e etnicidade. Esta mesma perspectiva é adotada por Goes (2013) ao estudar o grupo em Aracaju. Seguindo a mesma pista da etnicidade, o terceiro estudo é desenvolvido na cidade de Salvador por Teles (2015), que pesquisa sobre a produção da etnicidade na cidade de Salvador a partir das diferentes formas de preparo da comida chinesa, confrontando o espaço doméstico e o comercial. A associação da imigração e da gastronomia na cidade de Salvador volta a ser tema de investigação de Viana (2016), agora voltada aos costumes e práticas alimentares na comunidade formada por imigrantes e descendentes galegos na capital soteropolitana.

Duas outras nacionalidades são estudadas no período. A primeira são os libaneses e seus descendentes. Neste caso, o estudo procurou identificar e analisar as estratégias de ascensão social, econômica e política de Libaneses no Estado do Maranhão por meio de casamentos, escolarização e rede de relações pessoais (ASSIS, 2012). De volta ao Recife, Hazin (2016) estudou sobre o processo de assimilação de imigrantes palestinos na cidade e da reconstrução da identidade étnica por seus descendentes.

Assim como já observado no "primeiro olhar" os estudantes imigrantes também são tema de dissertações e teses. Neste caso, encontramos pesquisas sobre a presença de estudantes imigrantes originários de países africanos na cidade de Fortaleza. Langa (2016) estudou a reconfiguração identitária a partir da correlação entre origem africana, a condição de estudante e de imigrante temporário. Outro estudo sobre estudantes originários da África lusófona destaca as condições sociais, políticas e econômicas dos países de origem, sobre os impasses da decisão de não retorno e sobre as condições de integração à sociedade acolhedora (TCHAM, 2016). Uma outra pesquisa analisou as possibilidades de contribuição em seu retorno ao país de origem por parte dos estudantes inseridos em programas de mobilidade (LIMA, 2013).

Por último, face ao crescimento do número de imigrantes em Fortaleza no início do século XX, Guerra (2007) indaga, em sua dissertação de mestrado, sobre a existência de 
políticas imigratórias no Ceará. Um quinto estudo sobre africanos é desenvolvido por Barreto (2009) ao dedicar sobre as representações sociais e a qualidade de vida do grupo na cidade de João Pessoa. O interesse sobre modo de vida e sociabilidades também é o objeto de estudo da tese de doutorado de Viana (2012) que, a partir do conceito de configuração de Norbert Elias, investigou a presença de imigrantes de várias nacionalidades na cidade de Natal na passagem do século XX para o XXI. O interesse por aspectos mais subjetivos e individuais da experiência migratória como expressão do cosmopolitismo é, também, tema da tese de doutorado de Morales (2011), que estudou a presença e trajetória de imigrantes de várias origens como parte do fluxo norte-sul na cidade de Salvador.

Após a identificação do foco de estudo das dissertações e teses consultadas nos três períodos por nós definidos, podemos, em um balanço preliminar, dizer que os judeus é o grupo mais estudado, seguido do número de dissertações e teses que não focam em uma nacionalidade específica. Outros estudos foram desenvolvidos sobre chineses (4) e portugueses (4), africanos em geral (3), alemães (3), espanhóis (2), japoneses (2), italianos (2) e guineenses, palestinos e libaneses, uma vez.

Por último, com base na exposição acima e após agregarmos as palavras-chaves indicadas pelas/os autoras/es das dissertações e teses, podemos conhecer os enfoques mais recorrentes sobre imigração no Nordeste brasileiro. Questões relacionadas às identidades (21) e modos de vida (14) são os mais recorrentes. Na sequência encontramos os estudos sobre aspectos econômicos (11) e políticos (9). Temas relacionados aos fluxos migratórios, como fatores de repulsão e atração, diáspora, retorno, e sobre educação, redes e religião aparecem com menor número.

\section{Considerações finais}

Pode-se dizer que dissertações de mestrado e teses de doutorado consultadas apontam para uma mudança significativa das nacionalidades mais estudadas. Se no primeiro e segundos períodos observamos o foco em nacionalidades mais tradicionais, especialmente, de origem europeia, no terceiro período observamos um maior número de estudos sobre judeus, chineses, palestinos e africanos. Ainda que seja necessário reunir mais dados e aprofundar a análise, podese dizer que o interesse pela comunidade judia, em particular, na cidade do Recife, pode estar relacionada à chegada de descendentes do grupo nas universidades e de seu interesse sobre a história de seus antepassados. Em relação a imigrantes de países africanos, pode-se cogitar que o aumento do número de imigrantes do grupo decorra principalmente pela presença de estudantes universitários daquele continente em programas de mobilidade.

De acordo com as dissertações e teses consultadas, nos estudos que focaram no período compreendido entre as últimas décadas do século XIX e as primeiras do século XX, os temas mais recorrentes são economia, sociabilidades, etnicidade, aculturação; igreja e religião e trabalho. Outros temas tais como, motivações, gênero e educação, aparecem em apenas um dos trabalhos consultados

Observamos ainda uma mudança do recorte temático nos estudos migratórios. $\mathrm{O}$ interesse pelo tema da etnicidade, identidades e alteridades, passa a compor a preocupação de quase um terço dos trabalhos consultados. $\mathrm{O}$ crescimento do interesse por questões culturais em detrimento, por exemplo, das relacionadas à economia, observada no período anterior, é 
ainda maior se considerarmos que os temas sobre discriminação e memória somam $40 \%$ das dissertações e teses que estudaram o período.

Os dois olhares lançados sobre a imigração no Nordeste nos permitem responder, ainda que não completamente, as perguntas elencadas na introdução. Primeiro, sim, há imigrantes nos estados do Nordeste brasileiro e eles se fazem presentes em todos os períodos estudados, com maior ênfase no período do final do século XIX e início do século XX e na passagem deste para o século XXI. O período intermediário foi objeto de poucos estudos o que, como dissemos, pode estar relacionado à diminuição do fluxo imigratório o que, aliás, é comum a todo o país.

$\mathrm{O}$ estudo que deu origem ao artigo nos permite dizer que homens e mulheres nascidos em outros países se interessaram e se interessam pelo Nordeste por vários motivos. De modo geral, destacamos que estes imigrantes vêm se inserindo sob a condição de trabalhadores, empresários e, mais recentemente, como estudantes. Estas três categorias, no entanto, precisam ser desdobradas em suas várias possibilidades. Por exemplo, observa-se a presença de trabalhadores voltados às atividades rurais, especialmente no contexto do fim da escravidão. Mas há também trabalhadores urbanos que se dirigiram para as grandes capitais da região.

De forma análoga, pode-se dizer em relação aos empresários. Se hoje podemos encontrar grandes investidores, a presença de empresários imigrantes é parte da história da região. Judeus, libaneses, sírios, italianos, alemães, entre outras nacionalidades, atuaram no comércio local de maneira marcante. A partir de sua inserção seja como trabalhadores, seja como empresários, seja agora como estudantes, de acordo com as dissertações e teses consultadas, mulheres e homens imigrantes, protagonizaram conflitos e mudanças significativas. Em geral, são vistos com desconfiança seja pelo Estado brasileiro, seja pela população. Neste sentido, sofreram perseguições legais e viram suas casas e estabelecimentos comerciais serem alvo de depredação. Mas, também, atuaram de modo decisivo na cena política, dando origem a novas elites na cena cultural e arquitetônica. Merece destaque a importância dada por estudiosas/os sobre a dimensão da religiosidade, em especial, entre judeus e seus descendentes.

Em última análise, o presente artigo aponta para um lugar de grande importância de imigrantes para a história do Nordeste brasileiro. Mesmo em menor número do que os observados nas regiões sul e sudeste é possível afirmar que imprimiram sua presença seja no campo político, seja no campo econômico, ou ainda, cultural das cidades para onde se dirigiram e, atualmente se dirigem.

\section{Referências Bibliográficas}

ARAÚJO, Maria Gilda F. Colonização e imigração no ocaso do escravismo em Pernambuco. 1988. Dissertação (Mestrado) - Centro de Filosofia e Ciências Humanas, Programa de Pósgraduação em História, Universidade Federal de Pernambuco, Recife, 1988.

ASSIS, Ingrid P. Descendentes de libaneses na política do Maranhão: ascensão econômica, relações pessoais e afirmação política. 2012. Dissertação (Mestrado em Ciências Sociais) Programa de Pós-graduação em Ciências Sociais, Universidade Federal do Maranhão, São Luís, 2012.

BANINGER, Rosana, DEMÉTRIO, Natália B., DOMINICONI, Jóice (Coord.). Atlas temático. Campinas, SP: Núcleo de Estudos de População “Elza Berquó” - Nepo/ Unicamp, 2020. 
BARRETO, Lucia Maria S. Representação social dos imigrantes africanos acerca da qualidade de vida e do bem-estar-subjetivo. 2009. Tese (Doutorado em Psicologia) - Programa de Pós-graduação em Psicologia, Universidade Federal da Paraíba, João Pessoa, 2009.

BRASIL. Lei $n^{o}$ 13.445, de 24 de maio de 2017. Lei de Migração. Disponível em: http://www.planalto.gov.br/ccivil_03/_ato2015-2018/2017/lei/113445.htm. Acesso em: 14 nov. 2020.

BRITO, Creso N. M. Ressignificações identitárias: o caso dos B'nei Anussim em Recife (19702000). 2014. Dissertação (Mestrado em História) - Centro de Filosofia e Ciências Humanas, Programa de Pós-graduação em História, Universidade Federal Rural de Pernambuco, Recife, 2014.

CÂMARA, Bruno A. D. O 'retalho' do comércio: a política partidária, a comunidade portuguesa e a nacionalização do comércio a retalho, Pernambuco 1830-1870. Recife, 2012. Tese (Doutorado) - Centro de Filosofia e Ciências Humanas, Programa de Pós-graduação em História, Universidade Federal de Pernambuco, Recife, 2012.

CARVALHO, Sandra R. O projeto de ser na imigração: uma perspectiva fenomenológicoexistencial. 2016. Dissertação (Mestrado em Psicologia) - Programa de Pós-graduação em Psicologia, Universidade de Fortaleza, Fortaleza, 2016.

CUNHA, Keila S. F. A música do Shabat em Recife. 2011. Dissertação (Mestrado em Música) -Programa de Pós-graduação em Música, Universidade Federal da Paraíba, João Pessoa, 2011.

ENNES, Marcelo Alario. A imigração estrangeira para o Brasil. História (São Paulo). v. 30, n. p. 312-334. 2011.

FARIA, Erivam R. Italianos no Príncipe oitocentista: o outro e o mesmo na sociabilidade cotidiana. 2004. Dissertação (Mestrado em Ciências Sociais) - Programa de Pós-graduação em Ciências Sociais, Universidade Federal do Rio Grande do Norte, Natal, 2004.

FAUSTO, Boris et al. Imigração e política em São Paulo. São Paulo: Sumaré, 1995.

FAUSTO, Boris. Historiografia da imigração para São Paulo. São Paulo: Sumaré, 1991.

FERRAZ, Luiz P. P. “Deus te leve a Pernambuco”: antilusitanismo, legislação e estatística na história da imigração Portuguesa para Pernambuco (1945 - 1964). 2014. Dissertação (Mestrado em História) - Centro de Filosofia e Ciências Humanas, Programa de Pós-graduação em História, Universidade Federal de Pernambuco, Recife, 2014.

FONSECA, Juíra J. O Klientelshik: relações de solidariedade e troca no comércio ambulante do Recife no início do século XX'. 2002. Dissertação (Mestrado em Antropologia) - Programa de Pós-Graduação em Antropologia, Universidade Federal de Pernambuco, Recife, 2002.

FRANKLIN, Ruben M. "Gallegos”, "gombadres" e negócios: os imigrantes libaneses na Praça Mercantil da cidade de Fortaleza-CE (1890 - 1930). 2011. Dissertação (Mestrado em História) - Programa de Pós-Graduação em História, Universidade Federal do Ceará, Fortaleza, 2011.

GOES, Allisson G. S. Processos Identitários e a Produção da Presença Chinesa em Aracaju. 2013. Dissertação (Mestrado em Sociologia) - Programa de Pós-graduação em Sociologia, Universidade Federal de Sergipe, São Cristóvão, SE, 2013.

GRÜN, Roberto. Negócios \& famílias: armênios em São Paulo. São Paulo: Sumaré, 1992.

GUERRA, Danyelle M. R. Redes sociais de migração como crítica social às políticas públicas: estudo de casos em Fortaleza. 2007. Dissertação (Mestrado em Políticas Públicas) - Programa de Pós-graduação em Políticas Públicas, Universidade Estadual do Ceará, Fortaleza, 2007. 
HAZIN, Hissa M. Imigrantes palestinos, identidades brasileiras: compreendendo a identidade Palestina e as suas transformações. 2016. Dissertação (Mestrado em Antropologia) - Centro de Filosofia e Ciências Humanas, Programa de Pós-graduação em Antropologia, Universidade Federal de Pernambuco, Recife, 2016.

JESUS, Elivaldo S. Os nipo-baianos de Ituberá: trajetórias, memórias e identidades de imigrantes no baixo-sul da Bahia (1953-1980). 2015. Tese (Doutorado em Cultura e Sociedade) - Programa de Pós-Graduação em Cultura e Sociedade, Universidade Federal da Bahia, Salvador, BA, 2015.

JONES, Cleiton M. “Vem aí a Imigração”: expectativas, propostas e efetivações da imigração na Bahia (1816-1900). 2014. Dissertação (Mestrado em História) - Programa de PósGraduação em História, Universidade Federal da Bahia, Salvador, BA, 2014.

KAUFMAM, Tania N. Etnia, credo ou nação explicações de uma identidade. 1991. Dissertação (Mestrado em Antropologia) - Centro de Filosofia e Ciências Humanas, Programa de Pós-graduação em Antropologia, Universidade Federal de Pernambuco, Recife, 1991.

KLEIN, Herbert S. Imigração espanhola no Brasil. São Paulo: Sumaré, 1994.

LACERDA, Maria Lana M. "Súditos Do Mal": o cotidiano da repressão policial sobre alemães em Pernambuco (1937-1945). 2006. Dissertação (Mestrado) - Centro de Filosofia e Ciências Humanas, Programa de Pós-graduação em História, Universidade Federal de Pernambuco, Recife, 2006.

LANGA, Ercilio N. B. Diáspora africana em Fortaleza no século XXI: ressignificações identitárias de estudantes imigrantes. 2016. Tese (Doutorado em Sociologia)-Programa de Pósgraduação em Sociologia, Universidade Federal do Ceará, Fortaleza, 2016.

LEWIS, Susan. Pernambuco e o anti-semitismo no Estado Novo. 1997. Tese (Doutorado em Ciências Políticas) - Centro de Filosofia e Ciências Humanas, Programa de Pós-graduação em Ciências Políticas, Universidade Federal de Pernambuco, Recife, 1997.

LIMA, Isabela A. Negociando identidades: os fatores políticos e a ressignificação da identidade judaica: o caso da comunidade judaica em Pernambuco. 2004. Dissertação (Mestrado em Antropologia) - Centro de Filosofia e Ciências Humanas, Programa de Pós-graduação em Antropologia, Universidade Federal de Pernambuco, Recife, 2004.

LIMA, Keite Maria S. N. Entre a ferrovia e o comércio: urbanização e vida urbana em Alagoinhas (1868-1929). 2010. Dissertação (Mestrado em História) - Programa de PósGraduação em História, Universidade Federal da Bahia, Salvador, BA, 2010.

LIMA, Samuel A. Vidas em trânsito: um olhar sobre a formação guineense e seus impactos no retorno ao continente africano. 2013. Dissertação (Mestrado em Políticas Públicas) - Programa de Pós-graduação em Políticas Públicas, Universidade Estadual do Ceará, Fortaleza, 2013.

LIRA, Henrique J. B. Colonos e colônias: uma avaliação das experiências de colonização agrícola na Bahia na segunda metade do séc. XIX. 1982. Dissertação (Mestrado em Ciências Sociais) - Programa de Pós-Graduação em Ciências Sociais, Universidade Federal da Bahia, Salvador, BA, 1982.

LUDERMIR, Rosa B. Um lugar judeu no Recife: a influência de elementos culturais no processo de apropriação do espaço urbano do bairro da Boa Vista pela imigração judaica na primeira metade do século XX. 2005. Dissertação (Mestrado em Desenvolvimento Urbano) Programa de Pós-graduação em Desenvolvimento Urbano, Universidade Federal de Pernambuco, Recife, 2005. 
MAGALHÃES, Marcelo V. Sírios e libaneses na cidade de São Luís (1885-1930): entre táticas e representações. 2009. Dissertação (Mestrado em História) - Programa de Pós-Graduação em História, Universidade Federal do Ceará, Fortaleza, 2009.

MARTINEZ, Martin F. Entre o sakura e as uvas: Transformações e continuidades familiares, organizacionais e identitárias entre os nikkeis do Vale do São Francisco. Uma etnografia sobre trajetórias na agricultura irrigada. 2016. Tese (Doutorado em Antropologia) - Centro de Filosofia e Ciências Humanas, Programa de Pós-graduação em Antropologia, Universidade Federal de Pernambuco, Recife, 2016.

MONTEIRO, Tania P. Portugueses na Bahia na segunda metade do século XIX: imigração e comércio. 1985. Dissertação (Mestrado em História) - Programa de Pós-Graduação em História, Universidade Federal da Bahia, Salvador, BA, 1985.

MORALES, Anamaria. Vidas imaginadas na migração Norte-Sul: europeus na Bahia da globalização. 2011. Tese (Doutorado em Antropologia) - Programa de Pós-Graduação em Antropologia, Universidade Federal da Bahia, Salvador, BA, 2011.

MUNZ, Aristóteles V. S. Processo de identificação: um estudo de caso da comunidade judaica do Recife e sua relação com o Estado de Israel. 2008. Dissertação (Mestrado em Sociologia) Centro de Filosofia e Ciências Humanas, Programa de Pós-graduação em Sociologia, Universidade Federal de Pernambuco, Recife, 2008.

OLIVEIRA, Yolanda Maria de. O Colégio Israelita Moysés Chvarts: tradição e construção da identidade judaica recifense. 2008. Dissertação (Mestrado em Educação) - Centro de Filosofia e Ciências Humanas, Programa de Pós-graduação em Educação, Universidade Federal de Pernambuco, Recife, 2008.

PEREIRA, Marcelo; GOES, Allisson; ENNES, Marcelo. Mecanismos de solidariedade étnica/nacional e imigração: chineses e sul-coreanos em Aracaju/SE. Plural, São Paulo, n.1, v.27. 2020.

PERES, Victor H. L. Os "Chins" nas sociedades tropicais de plantação estudo das propostas de importação de trabalhadores chineses sob contrato e suas experiências de trabalho e vida no Brasil (1814 -1878). 2013. Dissertação (Mestrado em História) -Centro de Filosofia e Ciências Humanas, Programa de Pós-graduação em História, Universidade Federal de Pernambuco, Recife, 2013.

POLÍCIA FEDERAL. MJSP. Diretoria Executiva. Coordenação-Geral de Polícia de Imigração. Imigração Venezuela/Brasil. 2019. Disponível em: http://www.pf.gov.br/servicospf/imigracao/apresentcao-policia-federal-ate-abril-de-2019.pdf/view. Acesso em: 14 nov. 2020.

RABELLO, Evandro. Deutschtum na Bahia: a trajetória dos imigrantes alemães em Salvador. 2009. Dissertação (Mestrado em Antropologia) - Programa de Pós-Graduação em Antropologia, Universidade Federal da Bahia, Salvador, BA, 2009.

SAKURAI, Célia. Romanceiro da imigração japonesa. São Paulo: Sumaré, 1993.

SALLES, Maria do Rosário R. Médicos italianos em São Paulo (1890 - 1930): um projeto de ascensão social. São Paulo: Sumaré, 1997.

SANCHES MARTIN, Sebastian. A imigração espanhola para o Nordeste. 1979. Dissertação (Mestrado em História) -Centro de Filosofia e Ciências Humanas, Programa de Pós-graduação em História, Universidade Federal de Pernambuco, Recife, 1979. 
SILVA, Marcos A. Guanxi nos trópicos: um estudo sobre a diáspora chinesa em Pernambuco. 2008. Dissertação (Mestrado em Antropologia) - Centro de Filosofia e Ciências Humanas, Programa de Pós-graduação em Antropologia, Universidade Federal de Pernambuco, Recife, 2008.

SILVA, Marina Helena Chaves. Vivendo com o outro: os alemães na Bahia no período da II Guerra Mundial. 2007. Dissertação (Doutorado em História) - Programa de Pós-Graduação em História, Universidade Federal da Bahia, Salvador, BA, 2007.

SILVA, Valéria A. T. Comunidade judaica do Recife: possibilidades e entraves ao diálogo intra-religioso entre judeus asquenazes, sefarades e messiânicos: o que os distancia o que os une. 2007. Dissertação (Mestrado em Ciências da Religião) - Programa de Pós-graduação em Ciências da Religião, Universidade Católica de Recife, Recife, 2007.

SOUZA, Cristina F. S. Piedade e Reforma Católica na Bahia: a atuação dos frades menores capuchinhos (1889-1924). 2005. Dissertação (Mestrado em História) - Programa de PósGraduação em História, Universidade Federal da Bahia, Salvador, BA, 2005.

TAVARES, Abel de Castro. Existem judeus em Fortaleza? Um estudo sobre identidade. 2003. Dissertação (Mestrado em Sociologia) -Programa de Pós-graduação em Sociologia, Universidade Federal do Ceará, Fortaleza, 2003.

TCHAM, Ismael. Estar, ficar e retornar: estudantes africanos no Brasil e os dilemas da migração. 2016. Tese (Doutorado em Antropologia) - Centro de Filosofia e Ciências Humanas, Programa de Pós-graduação em Antropologia, Universidade Federal de Pernambuco, Recife, 2016.

TELES, Ana Claudia V. S. "O dendê no wok": um olhar antropológico sobre a comida chinesa em Salvador, Bahia. 2015. Tese (Doutorado em Antropologia) - Programa de Pós-Graduação em Antropologia, Universidade Federal da Bahia, Salvador, BA, 2015.

TRUZZI, Oswaldo M. S. Patrícios: sírios e libaneses em São Paulo. São Paulo: Hucitec, 1997. VIANA, F. P. A mesa galega na Bahia: a alimentação dos imigrantes galegos e descendentes em Salvador. 2016. Doutorado. Antropologia. UFBA Tese (Doutorado em Antropologia) Programa de Pós-Graduação em Antropologia, Universidade Federal da Bahia, Salvador, BA, 2016.

VIANA, Thereza Cristina B. S. Modos de ser e modos de viver: a trajetória dos estrangeiros em Natal/RN. 2012. Tese (Doutorado em Ciências Sociais) - Programa de Pós-graduação em Ciências Sociais, Universidade Federal do Rio Grande do Norte, Natal, 2012. 